\title{
Ética e cuidados paliativos: o que os médicos sabem sobre o assunto?
}

Izabela Dias Brugugnolli ${ }^{1}$, Ricardo Alessandro Teixeira Gonsaga ${ }^{2}$, Eduardo Marques da Silva ${ }^{3}$

\section{Resumo}

A partir do novo Código de Ética Médica brasileiro ficou estabelecido que o médico deve empregar cuidados paliativos na impossibilidade de cura. O objetivo do estudo foi conhecer o estado atual dessa prática. Para tal, conduzimos um estudo epidemiológico transversal quantitativo com os médicos do corpo clínico de um complexo de hospitais-escola quanto aos preceitos éticos implicados no exercício dos cuidados paliativos. Ao se questionar o médico sobre os seus objetivos no cuidado de um paciente, segundo os preceitos da ética médica, a maioria constrói respostas incompletas, apenas $28,9 \%$ responderam diretamente que empregariam os cuidados paliativos. A maioria dos médicos $(59,2 \%)$ ligam os cuidados paliativos somente ao alívio do sofrimento e qualidade de vida e para $38,2 \%$ deles a idade ainda é fator de influência importante na indicação. Logo, o conhecimento dos médicos em atividade sobre o tema é precário e medidas de educação médica se fazem necessárias.

Palavras-chave: Cuidados paliativos. Ética médica.

\section{Resumen}

\section{Ética y cuidados paliativos: ¿qué saben los médicos al respecto?}

A partir del nuevo Código de Ética Médica en Brasil (2010) se establece que el médico debe emplear cuidados paliativos en la imposibilidad de cura. El objetivo del estudio fue conocer el estado actual de esa práctica. Por esta razón, llevamos a cabo un estudio epidemiológico transversal, cuantitativo, con los médicos de un complejo de hospitales-escuelas en cuanto a precepticos éticos relacionados con el ejercicio de los cuidados paliativos. Al cuestionarse al médico acerca de sus objetivos en el cuidado de un paciente, de acuerdo a los preceptos de la ética médica, la mayoría construye respuestas incompletas, sólo el $28,9 \%$ respondieron directamente que emplearían los cuidados paliativos. La mayoría de los médicos $(59,2 \%)$ se refieren los cuidados paliativos solamente al alivio del sufrimiento y la calidad de vida y, para $38,2 \%$ de ellos, el factor edad es todavía una importante influencia en la indicación. Luego, el conocimiento de los médicos sobre el tema es precario y las medidas de la educación médica se hacen necesarias.

Palabras-clave: Cuidados paliativos. Ética médica.

\section{Abstract \\ Ethics and palliative care: what do physicians know about it?}

According to the new Code of Medical Ethics (2010) in Brazil it was established that physicians should employ palliative care when the cure is not possible. The aim of the study was to know the current state of this discussion. To this end, we have conducted a transversal quantitative epidemiological study with physicians from the clinical staff of a complex of Hospitals Schools regarding ethics in Palliative Care. When questioning physicians about their goals in the care of a patient, according to medical ethics, most of them gave us incomplete responses. Only $28.9 \%$ answered straight away that they would use palliative care. Most physicians (59.2\%) only consider palliative care for pain relief and quality of life, and $38.2 \%$ regard age as an important factor for this indication. Therefore, the knowledge of practicing physicians on this topic is precarious and medical education measures are necessary.

Key words: Palliative care. Medical ethics.

\section{Aprovação CEP Fipa CAAE - 0011.0.218.000-11}

1.Graduada izabrug@hotmail.com 2. Mestre novo02@uol.com.br 3. Especialista dumarques@gmail.com - Faculdades Integradas Padre Albino, Catanduva/SP, Brasil. 
A partir do novo Código de Ética Médica (CEM) brasileiro, em vigor desde abril de 2010, ficou estabelecida de maneira regimental que o médico, ao não proporcionar a cura de uma doença, deve empregar todos os cuidados paliativos disponíveis pela ciência médica, além de dispor de todo o seu conhecimento e experiência para cuidar do paciente ${ }^{1}$. A morte é invariavelmente parte componente do cotidiano dos profissionais de saúde.

Com o avanço importante das tecnologias na medicina, a vida hoje pode ser prolongada artificialmente ${ }^{2}$. Especialidades cada vez mais subespecializadas permitem um foco completo nas doenças e não no indivíduo como um todo. Tratar de um indivíduo cuja morte não poderá ser evitada não fez parte da formação dos médicos e, muitas vezes, é visto como um fracasso por si mesmo e pelos outros ${ }^{3}$.

Surgem, na contramão deste processo, os cuidados paliativos, que têm como princípios a concepção de que a morte é um processo natural e humano, bem como a consequente prática adequada do cuidado no contexto da ortotanásia, que implica em não provocar eutanásia e tampouco induzir a distanásia dos pacientes nos seus últimos dias de vida ${ }^{4}$. Estudo com 901 médicos mostrou a diminuição de sintomas com abordagem paliativa em $78,1 \%$ dos casos ${ }^{5}$, além de evidências a favor de custo ${ }^{6}$ e ganho de sobrevida ${ }^{7}$.

Os cuidados paliativos são algo bastante recente no Brasil. Objetivando conhecer o estado atual dessa prática conduzimos um estudo com os médicos do corpo clínico de um complexo de hospitais-escola quanto aos preceitos éticos implicados no exercício dos cuidados paliativos.

\section{Material e método}

Trata-se de estudo epidemiológico transversal, quantitativo, incluindo médicos habilitados e inscritos no Conselho Regional de Medicina do Estado de São Paulo (Cremesp). O estudo abrangeu preceptores, residentes e autônomos do corpo clínico do Complexo de Hospitais-Escola "Padre Albino" e "Emílio Carlos", vinculado às Faculdades Integradas Padre Albino - curso de medicina da cidade de Catanduva-SP, sede de microrregião com 19 cidades e cerca de 200 mil habitantes, localizada no noroeste do Estado de São Paulo. Até a conclusão deste estudo, ao final do terceiro trimestre de 2011, a faculdade não disponibilizava carga teórica ou prática específica em cuidados paliativos. A disciplina, criada no início de 2012 para corrigir esta deficiência, contava com 10 horas-aula teóricas para alunos do $4^{\circ}$ ano e 24 horas-aula de enfermaria para os alunos do $6^{\circ}$ ano.

O instrumento de avaliação foi uma entrevista realizada com base em questionário semiestruturado, composto de duas partes: a primeira com questões sociodemográficas e a segunda com questões dissertativas. Só era possível visualizar uma questão em cada página, sem a possibilidade de voltar e modificar as respostas. Foram critérios de inclusão no estudo ser integrante do corpo clínico dos hospitaisescola mediante assinatura do termo de consentimento livre e esclarecido (TCLE).

Foram inclusas as questões sociodemográficas: nome, idade, especialidade médica, gênero, ano de formatura, grande área de atuação (clínica médica, clínica cirúrgica, ortopedia, pediatria, ginecologia e obstetrícia). As questões qualitativas envolviam perguntas sobre a ética médica envolvida no final de vida e cuidados paliativos (Anexo). As respostas dos médicos foram analisadas com base na proposta do discurso do sujeito coletivo (DSC), técnica de dupla representatividade ${ }^{8}$. O DSC é uma proposta explícita de reconstituição de um ser ou entidade empírica coletiva, opinante na forma de um sujeito de discurso emitido na primeira pessoa do singular. Por ter como fundamento a teoria da representação social e suas vertentes sociológicas, promove uma técnica de tabulação de dados qualitativos por meio de procedimentos que visam agregar depoimentos para expressar a ideia.

Tal técnica possibilita analisar o material verbal coletado nos depoimentos e deles extrair, de cada um, as ideias centrais ou ancoragens e suas correspondentes expressões-chave. Dessa maneira, surgem com as ideias centrais ancoragens e expressões-chave semelhantes em um ou vários discursos-síntese, que são os DSC - o que possibilita melhor dimensão da pesquisa, sem perder o caráter qualitativo.

\section{Resultados}

Conforme relação fornecida pela diretoria clínica dos hospitais-escola, foram enviados 103 questionários, dos quais 76 (73,8\%) foram devolvidos aos pesquisadores com o questionário e TCLE completos.

A mediana de idade dos participantes do estudo foi de 33, com mínima de 25 e máxima de 68 anos. A mediana do ano de formatura foi 2002 , com o mínimo de 1968 e máximo de 2002. Agrupando por tempo de formatura, 34,5\% dos entrevistados se formaram a menos de cinco anos; $19,7 \%$, de cinco a 
10 anos; 36,8\%, de 10 a 20 anos e 9,2\%, mais de 35 anos de formados. Quanto ao gênero, a maioria é composta de homens $(65,8 \%)$. Sobre a área de atuação, 30,3\% são clínicos; $25 \%$, cirurgiões; $14,5 \%$, ginecologistas e obstetras; $5,3 \%$, ortopedistas; $9,2 \%$, pediatras e $15,8 \%$ compõem as demais especialidades.

A resposta a cada questão foi classificada de modo a proporcionar um escalonamento relacionado a determinado nível de pontuação. Dividimos a pontuação com base nas palavras-chave da definição de cuidado do paciente, segundo o CEM brasileiro, as quais eram: proporcionar a manutenção ou qualidade de vida, informar o paciente sobre a doença e as possibilidades de tratamento e respeitar a decisão do paciente ${ }^{9}$. A pontuação era obtida de acordo com o número de palavras e/ou ideias mencionadas. Quando se questionou o médico sobre seus objetivos ao cuidar de um paciente, segundo os preceitos da ética médica, a maioria apresentou respostas incompletas (Tabela 1).

Tabela 1. Conhecimento médico sobre o que é cuidar de um paciente pela ética médica

\begin{tabular}{|c|c|}
\hline Pontuação* & Percentual \\
\hline \multicolumn{2}{|c|}{ Inadequada } \\
\hline Nenhum ponto & $5,3 \%$ \\
\hline \multicolumn{2}{|c|}{ Resposta incompleta } \\
\hline Um ponto & $64,5 \%$ \\
\hline Dois pontos & $28,9 \%$ \\
\hline \multicolumn{2}{|c|}{ Completamente correto } \\
\hline Três pontos & $1,3 \%$ \\
\hline
\end{tabular}

*Classificação relativa à definição do CEM brasileiro.

Da mesma forma, dividimos a pontuação com base nas palavras-chave da definição de cuidados paliativos, segundo a Organização Mundial da Saúde (OMS) ${ }^{10}$. A pontuação era obtida de acordo com o número de palavras e/ou ideias mencionadas na resposta. Ao indagar o médico sobre sua conduta ética perante o paciente sem possibilidade de cura as respostas foram, em $30,3 \%$ das vezes, voltar os objetivos para cuidar dos sintomas e/ou do sofrimento do doente; $28,9 \%$ responderam diretamente as palavras cuidados paliativos (Tabela 2).
Tabela 2. Conhecimento médico sobre o que propor ao doente sem possibilidade de cura

\begin{tabular}{|l|c|}
\multicolumn{1}{|c|}{ Resposta } & Percentual \\
\hline Cuidados paliativos & $28,9 \%$ \\
Qualidade de vida & $25,0 \%$ \\
Cuidar dos sintomas e/ou sofrimento & $30,3 \%$ \\
Resposta inadequada & $13,2 \%$ \\
Não respondeu & $2,6 \%$ \\
\hline
\end{tabular}

* Classificação relativa à definição da OMS.

Ao se abordar questões da finitude, $78,9 \%$ dos médicos acham que o paciente gostaria de morrer em casa; $15,8 \%$ não responderam e apenas 5,3\% julgaram que os pacientes gostariam de morrer no hospital. A maioria $(98,6 \%)$ declarou que os pacientes desejam morrer com familiares por perto; os demais $(1,4 \%)$ acrescentaram os amigos à resposta. Quando se pergunta diretamente o desejo do médi$c 0$, as respostas não são diferentes $(p=29,5)$, já que $75 \%$ deles gostariam de morrer em casa. Entretanto, $19,7 \%$ não souberam responder e 5,3\% gostariam de falecer no hospital. A maior parte $(97,3 \%)$ gostaria da família por perto e $2,7 \%$ responderam que gostariam de estar sozinhos nesse momento.

Quanto ao fato de atualmente, no Brasil, muitas pessoas morrerem em uma unidade de terapia intensiva (UTI) ou em enfermarias, os médicos participantes do estudo julgam que a situação decorre $42,1 \%$ das vezes do funcionamento do sistema de saúde brasileiro; $10,5 \%$ julgam estar errada a postura da equipe médica e $27,6 \%$ acham que o paciente e sua família não expressam sua vontade claramente. Apenas 7,9\% dos entrevistados julgam que o erro está nas três vertentes (sistema de saúde, equipe médica e paciente); $5,3 \%$ julgam estar errado tanto o sistema de saúde quanto a equipe médica; 3,9\% o sistema de saúde e o paciente e $1,3 \%$, a postura da equipe e o paciente. Somente 1,3\% não responderam.

Mesmo assim, 85,5\% julgam ser de grande importância abordar sistematicamente, no Brasil, o paciente e sua família quanto ao local prioritário para o óbito, ordem de não ressuscitação cardiopulmonar e autorização para procedimentos invasivos. Porém, $9,2 \%$ não consideram que isso seja válido e 5,3\% não 
souberam responder. $\mathrm{Na}$ abordagem direta sobre $\mathrm{o}$ autoconhecimento em cuidados paliativos, $47,4 \%$ admitem um conhecimento bom e suficiente no âmbito do tema; 44,7\%, regular e 7,9\%, insuficiente. Entretanto, apenas 2,6\% conseguiram responder corretamente a questão: o que você entende por cuidados paliativos? (Tabela 3). A maioria dos entrevistados ligou os cuidados paliativos apenas ao alívio do sofrimento físico e qualidade de vida $(59,2 \%)$.
Ao analisar a idade dos entrevistados em relação ao próprio julgamento do autoconhecimento em cuidados paliativos, os médicos mais jovens admitem não ter conhecimento suficiente sobre o tema. Os mais experientes, por sua vez, se julgam, na maioria das vezes, competentes para cuidar de um paciente com indicação de cuidados paliativos (Gráfico 1).

Tabela 3. O que os médicos entendem por cuidados paliativos?

\begin{tabular}{|c|c|c|}
\hline \multicolumn{2}{|l|}{ Respostas } & Percentual \\
\hline Alívio do sofrimento e qualidade de vida & \multirow{4}{*}{$\begin{array}{l}\text { Respostas } \\
\text { incompletas }\end{array}$} & $59,2 \%$ \\
\hline Alívio de sintomas físicos e outros (social, psicológico, espiritual) & & $3,9 \%$ \\
\hline $\begin{array}{l}\text { Alívio do sofrimento e qualidade de vida, além de alívio de sintomas físicos } \\
\text { e outros (social, psicológico, espiritual) }\end{array}$ & & $10,5 \%$ \\
\hline Alívio do sofrimento e qualidade de vida para o paciente e sua família & & $7,9 \%$ \\
\hline $\begin{array}{l}\text { Cuidado paliativo é a abordagem que promove qualidade de vida de } \\
\text { pacientes e seus familiares ante doenças que ameaçam a continuidade da } \\
\text { vida, mediante prevenção e alívio do sofrimento }{ }^{10}\end{array}$ & $\begin{array}{l}\text { Respostas } \\
\text { completas }\end{array}$ & $2,6 \%$ \\
\hline Não respondeu ou respondeu inadequadamente & & $15,8 \%$ \\
\hline
\end{tabular}

Gráfico 1. Impressão sobre o autoconhecimento em cuidados paliativos e faixa etária

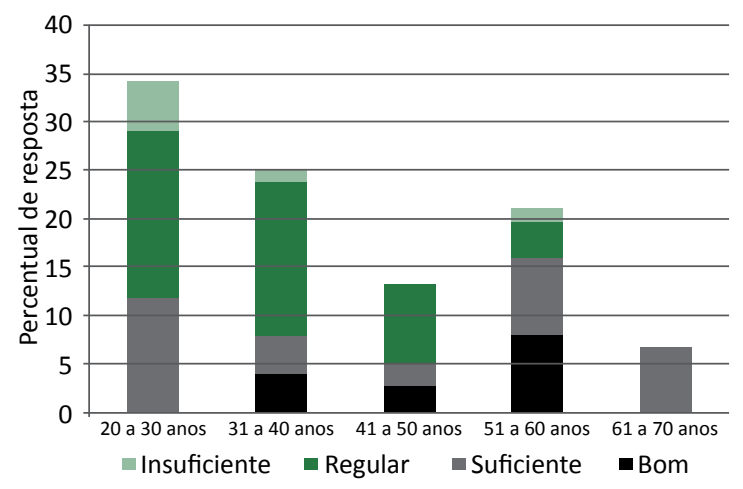

Teste $\chi^{2}(p=0,003)$

Para avaliar de fato o conhecimento dos entrevistados, propusemos a citação de alguma situação clínica em que indicariam cuidados paliativos: $61,8 \%$ responderam corretamente; 73\% foram situações ligadas a neoplasias; $21 \%$ às demais enfermidades e $6 \%$ dos entrevistados promoveram situações mistas. Então, formulamos situações clínicas neoplásicas e não neoplásicas nas quais todas seriam indicações de medicina paliativa: para um paciente com 40 anos, com CA inoperável, baixo desempenho funcional (KPS < 50 - Karnofsky Performance Status, índice utilizado para avaliação de performance funcional) e que não está em rádio nem quimioterapia, $50 \%$ dos médicos a indicariam. Para um paciente com 80 anos, totalmente dependente, acamado com doença renal crônica e desnutrido, 73,7\%. Em um jovem de 35 anos, com doença hepática Child-Pugh $C$ (índice utilizado para avaliar o grau de doenças hepáticas crônicas), porém não constante na fila de transplantes, $34,2 \%$ dos entrevistados consideraram a indicação.

Para um paciente com 51 anos e disfunção renal grau 5, impossibilitado de realizar diálise e sem indicação de transplante, 77,6\%. Observa-se, portanto, maior resistência em oferecer cuidados paliativos a pacientes mais jovens. Segundo $38,2 \%$ dos entrevistados, a idade é fator de influência na indicação dos cuidados paliativos. Apesar desses percentuais, 53,9\% afirmaram não ser influenciados pela idade e $7,9 \%$ não souberam opinar. 
Ao analisar outras vertentes dos cuidados paliativos excetuando-se o controle da dor e a proposição de melhor qualidade de vida, apenas $34,2 \%$ dos entrevistados responderam que se acompanhassem um doente em cuidados paliativos proporiam cuidar de sintomas não físicos, ou seja, sociais, espirituais e psicológicos. Somente 6,6\% proporiam uma abordagem com a família do doente. Ao excluir da pergunta a vertente dos cuidados físicos, a maioria $(55,3 \%)$ não se atenta aos pontos de atenção ao social, psicológico e espiritual. Quanto às decisões de fim de vida, $31,6 \%$ responderam que tratariam sobre o tema, e apenas 5,3\% fariam uma análise ampla sobre ambos os temas. Atentamos para o fato de que $18,4 \%$ não responderam ou responderam erroneamente.

Os momentos finais da vida do paciente foram investigados mediante análise de proposição de medidas médicas: $58,7 \%$ dos participantes do estudo proporiam medidas como sondas, cirurgias, medicações, se trouxerem alívio ao sofrimento; $20 \%$ conversariam com o doente para resguardar sua autonomia ou a do interlocutor responsável; 21,3\% não responderam ou o fizeram de maneira inadequada.

\section{Discussão}

Este trabalho apresenta, pela primeira vez, dados sobre o conhecimento dos médicos de um corpo clínico brasileiro sobre os cuidados paliativos. A limitação foi representada pela dificuldade de se elaborar um questionário para avaliação com perguntas objetivas, ou seja, múltipla escolha, e pelo fato de abranger conceitos éticos e de cuidados paliativos. Além disso, havia a possibilidade de influenciar os participantes do estudo com as alternativas por "bom-senso" e, dessa maneira, criar uma falsa impressão de conhecimento concreto do assunto.

Outra limitação foi a interpretação individual das respostas, baseadas em palavras-chave, o que é passível de um viés de interpretação. Tentou-se minimizar esse efeito baseando as respostas em fontes confiáveis, como o CEM brasileiro, com perguntas objetivas e, para analisar as respostas, dois examinadores diferentes - no caso de discrepância, houve o parecer de um terceiro examinador.

Buscando no universo estudado elementos que permitam relativa generalização dos resultados, buscou-se comparar o perfil dos médicos em estudo ao daqueles que compõem a classe no Estado de São Paulo. Quanto ao gênero, há no estado 106.536 médicos em atividade, dos quais $59,1 \%$ homens ${ }^{11}$, como na amostra. A idade dos participantes está abaixo da média estadual, que é de 45,1 anos $\pm 14,3^{11}$, fato explicado pela presença de médicos residentes e jovens preceptores em nosso serviço, o que também ratifica a média menor de anos de formado em comparação aos médicos do Estado de São Paulo $(19,9 \text { anos } \pm 13,6)^{11}$.

Os resultados mostram que o conhecimento sobre os deveres éticos de um médico brasileiro é bastante precário. A grande maioria dos profissionais não inclui em suas respostas nada sobre respeitar a autonomia do doente ou informá-lo do diagnóstico e prognóstico da enfermidade, como define o CEM brasileiro ${ }^{9}$. Acredita-se que essa informação se correlaciona com o fato de que muitas famílias, por suas crenças e costumes, prefiram esconder do próprio paciente o seu diagnóstico e decisões de finitude como a reanimação cardiopulmonar. Segundo estudo recente ${ }^{12}, 69 \%$ dos norte-americanos preferem que os médicos não revelem o real diagnóstico de doenças terminais aos seus entes queridos, e que a família se responsabilize sobre as decisões de fim de vida.

Embora 28,9\% dos médicos entrevistados tenham respondido que na impossibilidade de cura deve-se oferecer aos doentes cuidados paliativos, $55,3 \%$ das respostas evidenciavam apenas alguns dos objetivos dos cuidados paliativos (proporcionar qualidade de vida, cuidar dos sintomas e/ou sofrimentos). Entretanto, a maioria dos médicos não utilizam diretamente em suas respostas as palavras "cuidados paliativos", evidenciando o distanciamento do conceito correto. Além disso, verificou-se que boa parte dos entrevistados $(13,2 \%)$ ainda respondem a questão de maneira completamente inadequada. Esses dados corroboram com a necessidade de melhorar a educação em cuidados paliativos, como apontava em 1997 o The Lancet ${ }^{13}$.

No Brasil, não há dados sobre o conhecimento médico em relação ao tema. Porém, alguns autores ${ }^{14}$ estimam que haja deficiência sobre a medicina paliativa, já que o assunto não é de abordagem obrigatória nos currículos das escolas médicas para o Ministério da Educação (MEC) ${ }^{15}$. Os mesmos autores destacam que nos Estados Unidos da América (EUA) a educação sobre o cuidado com o paciente terminal é obrigatória no currículo das escolas médicas desde 2000 e foi reconhecida como especialidade médica em 2006. Mesmo assim, o reflexo desse conhecimento incompleto torna-se nítido quando se observa que metade dos pacientes morre com dor moderada ou severa, sem nenhuma prescrição analgésica, segundo um estudo multicêntrico esta- 
dunidense com 10 mil pacientes terminais avaliados (Support) ${ }^{16}$.

Os médicos pesquisados concordam que $78,9 \%$ dos pacientes gostariam de morrer em casa e com a família (98,6\%). Eles mesmos também têm esse desejo (75\% e 97,3\% respectivamente). Entretanto, observamos, segundo os registros do Datasus de 2010 , que $90,2 \%$ dos habitantes de Catanduva morrem em hospitais e 7,3\% em domicílio ${ }^{17}$. Apenas $7,9 \%$ dos entrevistados entenderam amplamente o porquê dessa disparidade entre intenção do paciente e corpo clínico e a realidade das estatísticas, haja vista que $42,1 \%$ dos médicos culpam apenas o funcionamento do Sistema Único de Saúde (SUS), 27,6\% apenas o paciente que não informa seus anseios e $10,5 \%$ apenas a classe médica e equipe de saúde.

Apesar de 47,4\% admitirem um conhecimento bom e suficiente no âmbito dos cuidados paliativos, apenas $2,6 \%$ conseguiram responder corretamente a questão específica. A maioria liga os cuidados paliativos apenas ao alívio do sofrimento físico e qualidade de vida, que apesar de ser um conceito correto é bastante amplo e subjetivo, pois ainda se difundem condutas que vão na contramão dos conceitos de medicina paliativa. A minoria cita questões espirituais, sociais e familiares. É preocupante, do ponto de vista bioético, o fato de significativa parcela dos médicos (13\%) ter respondido de maneira completamente inadequada.

Deve-se ressaltar que os médicos mais jovens se julgam não conhecedores do assunto, sublinhando a impreterível necessidade de se implantar já na grade curricular das escolas médicas e de enfermagem no Brasil a disciplina de cuidados paliativos ${ }^{18}$. As respostas deste grupo etário mostram ser preciso ocupar esse espaço para a educação médica continuada, que se abriu a partir do novo CEM brasileiro.

Quando propusemos ao médico exemplificar um caso com indicação de cuidados paliativos, grande parcela não conseguiu propor adequadamente (32\%) e dos que o fizeram corretamente, a maioria cita situações oncológicas. De acordo com um levantamento realizado de 1992 a 2000, nos EUA, 55\% das indicações de cuidados paliativos eram por neoplasias malignas, $45 \%$ para todas as demais doenças, por exemplo, doenças cardiovasculares (7\%), demências (7\%), doença pulmonar obstrutiva crônica $(4 \%)$ e doenças cerebrovasculares $(5 \%){ }^{19}$. Ainda notamos uma dificuldade em propor cuidados paliativos quando o paciente é jovem, o que de certa forma pode gerar internações, cirurgias e procedimentos desnecessários, gerando custo para o sistema de saúde e não benefício ao paciente e sua família.

\section{Consideração final}

O conhecimento dos médicos em atividade sobre o tema é precário e medidas de educação médica se fazem necessárias para suprir tal carência. A curto e médio prazos a alternativa seria implementar ações em educação médica continuada e, a longo prazo, a implantação definitiva da medicina paliativa na grade curricular das escolas médicas.

\section{Referências}

1. Neves NMBC, Siqueira JE. A bioética no atual código de ética médica. Rev. bioét. (Impr.). 2010;18(2):439-50.

2. Maciel MGS. Definições e princípios. In: Oliveira RA, coordenador. Cuidado paliativo. São Paulo: Cremesp; 2008. p. 15-32.

3. Bertachini L. Humanização e cuidados paliativos. In: Pessini L, Bertachini L, organizadores. São Paulo: Loyola; 2004.

4. Andrade JC, Andrade Filho ACC. Estamos preparados para a medicina paliativa? Revista Simbidor. 2002;3(1):8-19.

5. Schildmann J, Hoetzel J, Mueller-Busch C, Vollmann J. End-of-life practices in palliative care: a cross sectional survey of physician members of the German Society for Palliative Medicine. Palliat Med. 2010;24(8):820-7.

6. Morrison RS, Dietrich J, Ladwig S, Quill T, Sacco J, et al. Palliative care consultation teams cut hospital costs for medicaid beneficiaries. Health Aff. 2011;30(3):454-63.

7. Temel JS, Greer JA, Muzikansky A, Gallagher ER, Admane S, et al. Early palliative care for patients with metastatic non-small-cell lung cancer. $\mathrm{N}$ Engl J Med. 2010;363(8):733-42.

8. Lefevre F, Lefevre AMC. O sujeito coletivo que fala. Comunic Saúde Educ. 2006;10(20):517-24. 
9. Conselho Federal de Medicina. Código de Ética Médica. [Internet]. Brasília: CFM; 2011 (acesso 16 jun. 2012). Disponível: http://www.portalmedico.org.br/novocodigo/ integra.asp

10. Sepúlveda C, Marlin A, Yoshida T, Ullrich A. Palliative care: the World Health Organization's global perspective. J Pain Symptom Manage. 2002;24(2):91-6.

11. Biancarelli A, Cassenote A. Demografia médica no Brasil. In: Scheffer M, coordenador. São Paulo/Brasília: Cremesp/CFM; 2011. p. 118.

12. Lee A, Wu HY. Diagnosis disclosure in cancer patients - when the family says "no!". Singapore Med J. 2002;43(10):533-8.

13. Time for education in palliative care. The Lancet. 1997;349(9067):1.709.

14. Kira CM, Montagnini M, Barbosa SMM. Educação em cuidados paliativos. In: Oliveira RA, coordenador. Cuidado paliativo. São Paulo: Cremesp; 2008. p. 595-612.

15. Brasil. Ministério da Educação e Cultura. Diretrizes curriculares nacionais dos cursos de graduação em enfermagem, medicina e nutrição. [Internet]. Brasília; 2001 (acesso 16 jun. 2012). Disponível: http://portal.mec.gov.br/dmdocuments/ces1133.pdf

16. Connors AF, Jr, Dawson NV, Desbiens NA. A controlled trial to improve care for seriously ill hospitalized patients: the study to understand prognoses and preferences for outcomes and risks of treatments (support). Jama. 1995;274(20):1.591-8.

17. Brasil. Ministério da Saúde. Datasus: informações de saúde - mortalidade. [Internet]. (acesso 17 jul. 2012). Disponível: http://tabnet.datasus.gov.br/tabdata/livroidb/2ed/ CapituloC.pdf

18. Rodrigues IG. Cuidados paliativos: análise de conceito. [dissertação]. Ribeirão Preto: Universidade de São Paulo; 2004.

19. Leland JY. Death and dying: management of patients with end-stage disease. Clin Geriatr Med. 2000;16(4):875-94.

\section{Participação dos autores}

Izabela Dias Brugugnolli participou do planejamento do estudo, coleta de dados, análise estatística e redação final do artigo. Ricardo Alessandro Teixeira Gonsaga, do planejamento e orientação do estudo e redação final. Eduardo Marques da Silva, do planejamento do estudo, análise estatística e redação final. Todos leram e aprovaram o presente artigo.

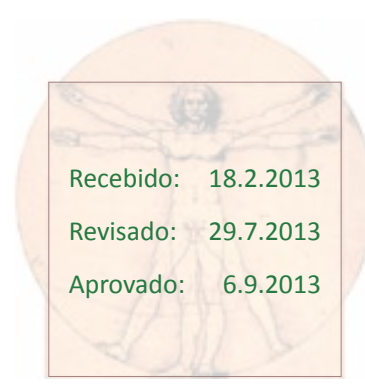


Anexo

\section{COLETA DE DADOS}

\section{Cuidados paliativos}

Nome:

Idade: anos

Especialidade:

Sexo: $F() M()$

Ano de formatura:

Grande área de atuação:

Clínica Médica ( )

Clínica Cirúrgica ( )

Ortopedia ( )

Pediatria ( )

Ginecologia e Obstetrícia ( )

Outra ( )

Perdeu algum ente próximo? ( ) Não

Pai ( )

Mãe ( )

Irmãos ( )

Filhos ()

Local do óbito?

Número de doenças crônicas que o entrevistado possui:

Nenhuma ( )

Uma ( )

Duas ( )

Três ou mais ( )

1. Pela ética médica, quais seus objetivos ao cuidar de um paciente?

2. Quando sabidamente a cura não é possível, qual passa a ser sua conduta ética perante o paciente?

3. Na sua opinião, onde a maioria dos pacientes que você atende gostaria de passar os momentos finais de vida e com quem?
4. E você, onde gostaria de passar os seus momentos finais e com quem?

5. Considerando que, à luz da medicina atual, a imensa maioria dos pacientes vão morrer no hospital ou na UTI, sozinho (fato), você acha que o erro está?

Na postura ética da equipe médica ( ) No funcionamento do sistema de saúde () No paciente e familiares que não expressam sua vontade claramente ()

6. Nos EUA e em alguns países da Europa existe a política de se abordar sistematicamente, em pacientes com doenças progressivas que podem levar à morte, questões sobre finitude como: quem tomará as decisões em caso de inconsciência? Qual o local prioritário para o óbito? Ordem de não ressuscitação cardiopulmonar etc. Você acha que essa abordagem sistemática seria benéfica no Brasil?

7. O seu conhecimento atual sobre cuidados paliativos é:

Bom ()

Suficiente ( )

Regular ()

Insuficiente ()

8. O que você entende por cuidados paliativos?

9. Além do controle da dor, o que um médico acompanhando um paciente em cuidados paliativos deve lhe proporcionar?

10. Além da esfera física do sofrimento, que outros temas você julga ético de serem abordados ao longo do processo de morte de um paciente?

11. Pensando num paciente em dias finais de vida, antes de propor medidas como medicamentos, sondas, cirurgias, quais possíveis benefícios e riscos devem ser levados em conta na tomada de decisão? 
12. Como você enxerga a influência da idade do paciente na indicação ou não de cuidados paliativos pela comunidade médica?

13. Existe algum exemplo de situação clínica em que você proporia cuidados paliativos a um paciente.

14. Em quais casos abaixo você proporia cuidados paliativos? a. Paciente, 40 anos, CA inoperável, com baixa performance funcional (KPS < 50), não está em RT nem QT ( ) b. Paciente, 80 anos, totalmente dependente, acamado com IRC e desnutrido ( )

c. Paciente, 35 anos, com doença hepática Child-Pugh C, porém não está na fila de transplantes ( )

d. Paciente, 62 anos, diabético, hipertenso e hepatopata, internado frequentemente por descompensação (albumina < 2,5) () 